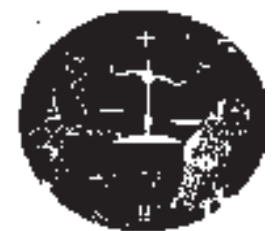

\title{
Punição e tratamento: as faces contraditórias DO SISTEMA PENITENCIÁRIO BRASILEIRO
}

\author{
DOI: $10.12957 /$ synthesis.2015.25835
}

\section{Lobelia dA SILVA FACEIRA*}

Resumo: O artigo foi produzido a partir de pesquisas desenvolvidas no Laboratório de Práticas Sociais e Pesquisas sobre Violência, vinculado ao Programa de Pós-Graduação em Memória Social (UNIRIO), que têm como objeto de estudo a memória social dos sistemas punitivos. Nesse sentido, o trabalho tem a proposta de apresentar reflexões críticas sobre as contradições implícitas no sistema penitenciário brasileiro, destacando sua proposta antagônica de configurar um espaço de privação de liberdade e tratamento penitenciário. Historicamente, as formas de punição atendem aos interesses ideológicos, políticos e econômicos da estrutura social. Pensando o cenário contemporâneo, as formas punitivas e coercitivas atendem à lógica restritiva e de desmonte do Estado Democrático de Direito e, paralelamente, à intensificação do Estado Penal e gestor de políticas públicas restritivas e assistencialistas.

Palavras-chave: Punição. Prisão. Política Pública. Tratamento Penal.

\section{Punishment and treatment: the contradictory faces of the Brazilian prison system}

Abstract: The article was produced from a developed research in Social Practices Laboratory and Research on Violence, linked to the Graduate Program in Social Memory (UNIRIO), which have as their study's object, the social memory of punitive systems. In this sense, the work has a proposal to present critical reflections on the implicit contradictions in the Brazilian prison system, highlighting its antagonistic proposal to set up a deprived area of freedom and prison treatment. Historically, forms of punishment meet the ideological, political and economic interests of the social structure. Thinking about the contemporary scene, punitive and coercive forms meet the strict logic and dismantle the democratic state and, in parallel, the intensification of the penal state and restrictive public policies and welfare manager.

Keywords: Punishment. Prison. Public Policy. Criminal Treatment.

*Professora Adjunta da Escola de Serviço Social e do Programa de Pós Graduação em Memória Social da Universidade Federal do Estado do Rio de Janeiro

\section{INTRODUÇÃO}

$\mathrm{O}$ artigo tem a proposta de apresentar reflexões sobre as contradições implícitas no cenário do sistema penitenciário brasileiro, sendo necessário conceituar historicamente as categorias teóricas prisão e punição.
Estudar as formas de punição é traçar uma linha cronológica muito clara, deixando explícita a correlação existente entre as formas de punição e a estrutura social, sendo esta caracterizada pelos quadros sociais, econômicos e políticos vigentes. 
A estruturação dos sistemas punitivos e penais está diretamente vinculada ao momento econômico vivenciado pela sociedade, estando inserida na dinâmica do sistema social em sua totalidade, não sendo um mero produto de uma lei específica. Se visitarmos brevemente a história, iremos observar inúmeros exemplos da vinculação das formas de punição com a dinâmica da estrutura social, tais como: a obrigatoriedade do trabalho dos presos nas galés ${ }^{1}$, no século XVI, que se deveu à escassez de trabalhadores livres, os quais se negavam a realizar insalubre tarefa; que a repressão à mendicância e vadiagem, contrárias aos valores da ascendente burguesia, determinou o surgimento das casas de correção no fim do século XVII.

Segundo Foucault (1987), o surgimento das prisões ocorreu na Antiguidade, quando o processo de reclusão não era julgado como sanção penal. O cárcere servia como meio de evitar que o criminoso se evadisse e quebrasse o cumprimento das penas, que consistiam em castigos corporais indignos, pois a prática da tortura era vista como instrumento legítimo de obtenção de prova do crime, além da própria pena de morte.

Tais práticas eram constituídas por meios coercitivos e de repressão ao sujeito, nas quais o corpo era considerado como um objeto de punição para aqueles que praticavam condutas desviantes. Deste modo, a tortura era tida como uma forma predominante de punição da sociedade feudal, baseada na relação de servidão que existia nesse modo de organização da produção e da sociedade, onde a nobreza detinha o poder econômico e político e a figura soberana era considerada uma representação de Deus, um ser divino e inquestionável. Nesse contexto, o crime era visto como pecado ou falta moral e religiosa, justificando o corpo como objeto de punição.

O processo de punição ocorria de forma pública, servindo como uma espécie de cerimônia de violência e crueldade, sendo transmitido como uma forma de exemplo para os demais sujeitos. Foucault (1987) nos aponta que a proporcionalidade existente entre crime e castigo (punição) atendia menos à gravidade do delito do que à condição social do sujeito censurado.

\footnotetext{
Uma pena, para ser suplício, deve obedecer a três critérios principais: em primeiro lugar, produzir uma certa quantidade de sofrimento que se possa, se não medir exatamente, ao menos apreciar, comparar e hierarquizar: a morte é um suplício na medida em que ela não é simplesmente a privação do direito de viver, mas a ocasião e o termo final de uma graduação calculada de sofrimentos (...). Além disso, o suplício faz parte de um ritual. É um elemento na liturgia punitiva, e que obedece a duas exigências. Em relação à vítima, ele deve ser marcante (...). E pelo lado da justiça que o impõe, o suplício deve ser ostentoso, deve ser constatado por todos, um pouco como seu triunfo (FOUCAULT, 1987, p.31)
}

Paralelamente ao suplício, no período da Idade Média, a indenização e a fiança eram as formas de punição eleitas para aqueles indivíduos que podiam realizar o seu pagamento, sendo elas graduadas de acordo com a classe social do infrator e de sua vítima. Ou seja, os indivíduos pertencentes à nobreza eram condenados ao pagamento de fiança ou ao exílio, enquanto os sujeitos pobres eram condenados ao suplício do corpo. Nessa época, não havia uma arquitetura penitenciária específica e os acusados eram mantidos encarcerados em torres, calabouços, conventos abandonados, aposentos, ruínas, castelos, palácios e outros, até a "solenidade" do julgamento.

Foucault (1987) considera que, historicamente, a horribilidade do mal cometido pelo acusado deveria ser representada no seu próprio corpo e na reparação do próprio mal causado. Essa representação também era entendida como uma forma de reafirmar a autoridade e o poder do soberano; seu caráter público serviria de exemplo a todos, e, assim, possuía função de prevenção da criminalidade.

Com o surgimento da industrialização e o desenvolvimento do modo de produção capitalista e, portanto, de uma nova forma de distribuição social e espacial das riquezas industriais cuja forma de organização não se concentrava apenas em propriedades, mas na produção e consumo de 
mercadorias, as quais necessitavam para a sua produção de matérias-primas, maquinaria específica, espaços para armazenamento da produção (e também da maquinaria) e força de trabalho, fez-se necessário pensar uma nova estratégia punitiva como condição de controle social.

Nesse contexto, a aplicabilidade da pena ao acusado foi sendo reformulada. O suplício dos corpos passou a receber críticas intensas por juristas e teóricos do Direito, sobretudo a partir da violência que era empregada neste exemplo de exercício legítimo do poder real; a partir daí é reclamada a justiça, a punição ao invés da vingança (Foucault, 1987).

Além da mudança do caráter punitivo, os crimes também se redimensionam, deixando a ênfase na dimensão de extrema violência e passando a se relacionar à gênese e intensificação das expressões da questão social. Nesse contexto, torna-se emergente a mudança na lei, no sentido de garantir proteção à propriedade privada. Toda esta reformulação faz parte de uma lógica denominada por Foucault (1987) de "economia do poder".

O verdadeiro objetivo da reforma, e isso desde suas formulações mais gerais, não é tanto fundar um novo direito de punir a partir de princípios mais equitativos; mas estabelecer uma nova "economia" do poder de castigar, assegurar uma melhor distribuição dele, fazer com que não fique concentrado demais em alguns pontos privilegiados, nem partilhado demais entre instâncias que se opõem; que seja repartido em circuitos homogêneos que possam ser exercidos em toda a parte, de maneira contínua e até o mais fino grão do corpo social (FOUCAULT, 1987, p. 101).

O criminoso agora não é caracterizado mais como um inimigo do soberano, mas como um inimigo público, um "inimigo do corpo social", consequentemente, o direito de punir deixa de se relacionar à vingança e passa a ser considerado uma ação de defesa da sociedade.

Neste contexto punitivo começa uma reorganização teórica da lei, modificando os mecanismos de punição e também a forma de se pensar a conceituação sobre crime e criminoso, baseada nos consecutivos princípios: o crime não está mais relacionado ao pecado, a uma indisciplina religiosa ou moral, "o crime ou infração penal é a ruptura com a lei civil explicitamente estabelecida no interior de uma sociedade pelo lado legislativo de poder público." (Foucault, 1974, p.64), ou seja, não há crime se não há lei que o determine previamente; outro princípio é o de que a lei defina o que é prejudicial à sociedade civil e ao Estado, quais são os comportamentos ou condutas consentidos e toleráveis e quais são os que precisam ser reprimidos; o último preceito estabelece que o crime não mais está associado ao pecado, passando a ser definido como um "dano social" sendo considerado um incômodo à sociedade. Logo, "o criminoso é aquele que danifica ou perturba a sociedade. O criminoso é o inimigo social." (Foucault, 1974, p.64)

Resultante desse processo histórico ocorre o surgimento e generalização da instituição penal no final do século XVIII e início do século XIX, sendo apresentada como uma forma "mais humana e inovadora" de tratamento da criminalidade, substituindo dessa forma a pena de suplício. De acordo com Foucault (1987), "Chegará o dia no século XIX, em que esse homem, descoberto no criminoso, se tornará um alvo da intervenção penal, o objeto que ela pretende corrigir e transformar (...)" (Foucault, 1987, p.65).

Os métodos de punição adaptaram-se à nova demanda social apresentada, especificamente à necessidade de força de trabalho e de disciplinamento da população em mendicância ou considerada criminosa. A falta de mão de obra, bem como o custo representado pela mendicância, fizeram com que o Estado endurecesse sua postura em relação à população improdutiva, criando, no final do século XVII, uma instituição com o fim de abrigá-los, nas casas de correção, limpando, assim, a estética das cidades e dando uma destinação útil a esse grupo.

As casas de correção surgiram na Inglaterra, onde se misturavam os princípios das casas de assistência aos pobres, das oficinas de trabalho e das instituições 
penais, para criar um ambiente cujo objetivo precípuo era transformar mendigos, prostitutas, ladrões, desempregados, ou seja, os marginalizados, em força de trabalho útil. Visando o objetivo de disciplinamento e de tratamento penal, essas casas adotavam a ideologia calvinista do trabalho como a essência da vida e utilizavam-se da religião para propagar a ideologia da disciplina e da disposição para o labor.

Ressaltamos que o aparecimento e expansão dessas instituições nos séculos XVII e XVIII destacam que a política institucional para as casas de correção na sociedade capitalista não era o resultado de um amor fraterno, solidário ou de responsabilidade social, mas a tentativa de criar um cenário que contribuísse com o desenvolvimento do sistema capitalista.

Nesse sentido, as redefinições da forma de punir obedecem a uma reestruturação social, ou seja, o abandono das práticas de suplício ao final do séc. XVII e ao longo do séc. XVIII vai se configurando a partir da necessidade de uma nova organização social. As prisões configuram-se como formas de punição inerentes à sociedade capitalista, considerando como castigo a privação da liberdade e, implicitamente, a privação da liberdade de produzir e consumir enquanto cidadão. A punição continua servindo ao caráter de prevenção em relação aos novos crimes, especificamente, aos crimes contra a propriedade privada

(...) os reformadores pensam dar ao poder de punir um instrumento econômico, eficaz, generalizável por todo o corpo social, que possa codificar todos os comportamentos e consequentemente reduzir todo o domínio difuso das ilegalidades (FOUCAULT, 1987, p. 114).

Em princípio, as casas de correção foram criadas com a intenção de "regenerar" aqueles indivíduos considerados "vagabundos", domesticando os corpos, fazendo-os dóceis, principalmente para suportar jornadas árduas de trabalho, sendo consideradas grandes fábricas onde o trabalho era atrelado à disciplina intensa, de forma a reeducar aqueles que lá estavam.

\begin{abstract}
E finalmente, o que se procura reconstruir nessa técnica de correção não é tanto o sujeito de direito, que se encontra preso nos interesses fundamentais do pacto social: é o sujeito obediente, o indivíduo sujeito a hábitos, regras, ordens, uma autoridade que se exerce continuamente sobre ele e em torno dele, e que ele deve deixar funcionar automaticamente nele (FOUCAULT, 1987, p. 148).
\end{abstract}

A instituição prisão, portanto, criada entre os séculos XVII e XVIII, constituiu-se como um dos mais eficientes mecanismos de controle social e coerção, vindo de um período histórico específico, compreendido entre o Feudalismo e a transição para o modo de produção capitalista. O germe da aparelhagem prisional já existia neste período preparando-se os corpos, tornando-os úteis e produtivos para o trabalho. Todavia, é somente no século XIX que a instituição prisão melhor se delineia, ao incorporar a penalidade de detenção.

As prisões funcionam seguindo a "lógica da disciplina", o que significa dizer que pertencem a uma engendrada estrutura que se exerce seguindo uma "codificação que esquadrinha ao máximo o tempo, o espaço, os movimentos", através do "controle minucioso das operações do corpo", buscando impô-lo "uma relação de docilidadeutilidade" (FOUCAULT, 1987, p.164). O corpo do condenado passa a ser um bem público, seu crime passa a ser visto como uma conduta antissocial e, portanto, o criminoso é um inimigo do povo. Como punição, o indivíduo é isolado socialmente. O castigo passa a ser a diretriz que move a pena de detenção, é preciso punir não somente o corpo, mas a alma também.

\footnotetext{
Mas a obviedade da prisão se fundamenta também em seu papel, suposto ou exigido, de aparelho de transformar os indivíduos. Como não seria a prisão imediatamente aceita, pois se só o que ela faz, ao encarcerar, ao retreinar, ao tornar dócil, é reproduzir, podendo sempre acentuá-los um pouco, todos os
}

[SYN]THESIS, Rio de Janeiro, vol.8, n 1, 2015, p. 127 - 137 
mecanismos que encontramos no corpo social (FOUCAULT, 1987, p. 6).

O poder disciplinar constrói uma sociedade disciplinar, adestrando, produzindo coletivamente corpos individualizados e dóceis. Trata-se de uma modalidade de poder produtivo, e não essencialmente restritivo, mutilador ou repressivo, que liga as forças para multiplicá-las e utilizá-las em sua totalidade, apropriando-se delas ainda mais e melhor. A ação do poder disciplinar é essencialmente produção de subjetividade moderna.

A prisão é organizada para proteger a sociedade contra perigos intencionais, tendo como foco principal a disciplina, a punição e manutenção da segurança, sendo caracterizada por uma rotina institucionalizada e massificada, muitas vezes, considerada e definida como um local de residência e trabalho. "A vida é então repartida de acordo com um horário absolutamente estrito, sob uma vigilância ininterrupta: cada instante do dia é destinado a alguma coisa, prescreve-se um tipo de atividade e implica obrigações e proibições." (FOUCAULT, 1987, p. 143).

O indivíduo preso participa de uma organização cumprindo as obrigações, delineando padrões de bemestar, valores, incentivos e sanções, passando por processos de ajustamento a um espaço de vigilância e a um sistema de comunicação vigiado e mediado.

Nesse sentido, a sociedade passa a legitimar a prisão a partir da proposta de punição, castigo e tratamento do preso, no qual o mesmo é considerado como um ser social em disfunção, que precisa do mecanismo de reparação, reeducação, reinserção e ressocialização.

Precisa ver como patologia o que a sociedade vê como mau comportamento, precisa considerar que a patologia necessita de tratamento porque significa a incapacidade e despreparo do paciente para viver em comunidade, precisa ver que o fracasso da mesma é devido ao caráter rebelde da perturbação (GOFFMAN, 1974, p. 282).

O sujeito que cometeu um ato criminoso é considerado patologicamente como um doente social, sendo necessários a privação da liberdade e o desenvolvimento de ações diversas de tratamento penal. Dentro deste contexto contraditório, o artigo tem a proposta de analisar a esfera de punição e tratamento penal implícita no sistema penitenciário brasileiro, sendo necessário caracterizar as práticas punitivas neste cenário.

\section{UM BREVE OLHAR SOBRE AS PRÁTICAS PUNITIVAS E O SISTEMA PENITENCIÁRIO BRASILEIRO}

As práticas punitivas no cenário brasileiro também são perpassadas historicamente pelo suplício do corpo, ou seja, a reparação do mal causado deveria ser representada no próprio corpo do condenado, reafirmando a autoridade e o poder do soberano.

No período colonial, a pena de morte fazia parte da legislação portuguesa, em particular, do Livro V das Ordenações Filipinas ${ }^{2}$. Como os reis deveriam ser misericordiosos, a pena de morte era utilizada somente como efeito inibidor e repressivo nos crimes de lesa-majestade, ou seja, crimes políticos e nas ocorrências envolvendo escravos rebeldes, deixando de alcançar outros crimes.

Com a reforma pombalina ${ }^{3}$ na segunda metade do século XVIII, passa-se à modernidade no que diz respeito às penas. Duas delas começam a sair de evidência - pena de morte e galés ${ }^{4}$ - ao passo que duas outras incidem com maior ênfase, que são: o trabalho forçado e as casas de correção.

Araújo (2009) relata, em Histórias das Prisões no Brasil, que no período do Império português no Brasil já havia a preocupação com a construção de um local seguro para deter os criminosos e principalmente os escravos, que compunham a metade da população da capital. Sendo assim, no período de 1747 a 1808 foram criadas no Rio de Janeiro as prisões: Ilha das Cobras, Fortaleza de Santiago e Fortaleza de Santa Bárbara (prisões militares espalhadas pela baía de Guanabara); Cadeia Pública (localizada no edifício do Senado da Câmara) e Calabouço (localizada na fortaleza de Santiago); e a Cadeia da Relação (localizada no prédio do palácio da Justiça, ao lado da residência do vice-rei, que se 
tornou posteriormente Paço Imperial com a chegada da família Real. O local é atualmente o Palácio Tiradentes).

Quando o prédio do Palácio da Justiça foi requisitado com o objetivo de alojar a comitiva real, os presos foram removidos para um cárcere eclesiástico construído pela Igreja em 1732, ao pé do morro da Conceição, abaixo do Palácio Episcopal e próximo às ruas da Prainha (atual Rua do Acre) e da Vala (atual Rua Uruguaiana). O Aljube, como era conhecido esse cárcere, tornou-se destino da maioria dos presos escravos ou livres de 1808 a 1856.

No Rio de Janeiro, nesse período histórico, metade da população de 170 mil habitantes era composta por escravos, controlados por tronco, ferros e prisão. Nesse período do século XVIII, as prisões encontravam-se superlotadas. Com a escassez de recursos, as autoridades utilizaram a mão de obra de escravos presos em obras públicas, o que gerou um duplo cativeiro.

Após o código criminal de 1830, a pena de morte deixou de aparecer na legislação de maneira geral, por influência da Igreja ou por influência do movimento iluminista do fim do século XVIII. Como pontuamos anteriormente, as formas punitivas se reestruturam e se modificam para atender às necessidades da ordem social e de desenvolvimento do próprio capitalismo.

No Brasil, o poder oficial utilizou a força policial para ordenar e retirar das ruas a mão de obra "despreparada" e "desqualificada", constituída, principalmente, pela grande massa de ex-escravos. Nesse sentido, a Casa de Correção da Corte era fundamental para o "ordenamento" social e mais adiante as Colônias Correcionais, sendo a da Ilha Grande uma das mais utilizadas devido ao seu isolamento geográfico da sociedade, que permitia ao Estado o uso da força distante dos olhares indesejados dos curiosos, da imprensa e de questionadores do regime imposto.

A instituição penal promoveu um conjunto de práticas ideológicas que visavam o disciplinamento e a "ressocialização" ("recuperação") por meio da educação pelo trabalho e religião.

A Constituição de 1824 e o Código Criminal de $1830^{5}$ introduziram a questão do aprisionamento moderno no país. Os estudiosos brasileiros, influenciados pela Escola Positivista de Cesare Lombroso (1836-1909), Raffael e Garofalo (18511934) e Eurico Ferri (1856-1929), evidenciaram a prisão como local de observação e pesquisa, principalmente a partir do indivíduo criminoso, objetivando o estudo da "personalidade criminosa", dos motivos dos crimes, dos antecedentes familiares e psíquicos, além de outras suposições. Nesse período, as prisões brasileiras adotaram os moldes das prisões dos países desenvolvidos, uma vez que os legisladores pressupunham um ideal de civilização baseado em instalações adequadas e boas condições de higiene, o que de fato nunca aconteceu, esbarrando sempre na burocracia estatal e na falta de recursos agregados à superlotação.

Em fevereiro de 1833, o governo escolheu um terreno situado na Rua Nova Conde, nas chácaras do Catumbi, região mais afastada da cidade, local de mangues e pântanos, para a construção da primeira penitenciária. As obras duraram de 1833 a 1850, tendo como planejamento inicial o modelo panóptico, desenhado pelo filósofo Jeremy Bentham (1785), constituído por uma torre central que permite a um vigilante observar todos os prisioneiros sem que estes possam saber se estão ou não sendo observados.

Porém, devido à falta de recursos financeiros foram construídos somente dois edifícios, um destinado à Casa de Correção da Corte, inaugurado em 1856, e outro destinado à Casa de Detenção, este de caráter provisório e que passou a ser definitivo com o passar do tempo. Os demais raios do desenho inicial panóptico nunca saíram da planta (ARAÚJO, 2009).

Em tese, o preso que passasse pela Casa de Correção seria "recuperado" pelo e para o trabalho, mas isso não saiu do campo jurídico. Na prática, as prisões cheias, a precariedade das instalações e a permanência de práticas ainda escravistas impediam que a "ressocialização" ou "profissionalização"

[SYN]THESIS, Rio de Janeiro, vol.8, n 1, 2015, p. 127 - 137 
acontecesse de fato com a massa carcerária. A justiça criminal baseou sua prática ideológica no trabalho e na disciplina, mas não pensou na inserção dessas pessoas no mercado de trabalho. Não ocorreram cursos efetivos, encaminhamentos a empresas ou qualquer tentativa de inserção de fato.

A Casa de Correção era, por vezes, o único espaço de educação cívica da população marginalizada que por ali passava. O aceitável e o não aceitável pela sociedade e seus códigos passavam por uma fronteira muito vulnerável: poderia ser preso um escravo fugitivo, um jogador de aposta não licenciada ou um acusado de vadiagem. No Código de 1890 existia um subgrupo de infrações de contravenção onde havia uma definição muito vaga do que era lícito e ilícito quanto a pequenos crimes, o que deixava com a polícia a responsabilidade de decidir (CHAZKEL, 2009). Esses infratores eram condenados inclusive à prisão com trabalho em penitenciárias agrícolas, em particular na Colônia Correcional de Dois Rios.

Percebemos aí a ideia de que a falta de trabalho era sinônimo de vadiagem, com o que concordam as elites brasileiras. Assim, diante desse problema somente a ação policial e a prisão poderiam atentar contra a vida e a propriedade dos cidadãos honestos, formadores da boa sociedade (ARAÚJO, 2009, p. 296).

A Casa de Correção foi concebida para acomodar detentos sentenciados à prisão com trabalho, sendo a mão de obra na mesma utilizada com trabalhos de exploração de pedreira, carpintaria, alfaiataria, encadernação e sapataria. Esperava-se que a produção dos presos fornecesse sustento para a prisão, mas pelo que parece não conseguiu custear os gastos, devido, em parte, à qualidade duvidosa dos produtos.

A Casa de Detenção abrigava todo tipo de prisioneiros acusados por variedade de crimes e acusações, sendo os mesmos homens livres ou escravos. "Eles permaneciam em custódia do Estado mesmo que não tivessem sido indiciados por crime nenhum e eram compelidos a trabalhar para o governo, principalmente nos serviços e projetos de infraestrutura pública.” (CHAZKEL, 2009, p. 11).

Antes de chegarem à Casa de Detenção, os presos passavam pelo Instituto Forense, local em que faziam exame médico para determinação de estado mental, além de qualificar aptidão para o trabalho. Chegando lá, produziam grande parte do material que a instituição ou o Estado precisasse, como: bolsas para o departamento de Correios, coldres para os policiais, equipamentos usados em animais e no transporte de prisioneiros (CHAZKEL, 2009).

A designação "casa de correção" já explicita a concepção de que o criminoso deveria ser corrigido, não com castigo físico, mas através do trabalho numa forma de edificação pessoal e combate à ociosidade. Posteriormente, a educação também será vista como uma espécie de redentora dessas almas, que deveriam voltar a um estado de normatização social. Mais uma vez, reforçamos o caráter de anomalia pelo qual o criminoso é visto, não se tendo uma visão do crime como uma construção social. Dessa forma, todo aquele que se afasta das normas sociais, sobretudo cometendo um crime ou delito, deve ser corrigido, normatizado para que seja reinserido à sociedade. Essa visão normativa do sujeito irá ser ratificada e reforçada após a Proclamação da República, principalmente pelo viés econômico, das transformações que o país vinha sofrendo nesse campo.

\footnotetext{
A prisão, como sistema disciplinar que dispensa a violência física direta, faz entrar a sociedade brasileira na era da penalidade carcerária. (...) A racionalização das formas de produção no campo, o predomínio do modo de produção capitalista, a emergência de um setor industrial mecanizado completam a disciplinarização, que consagra o fim da escravidão e dos castigos corporais e inaugura a época da racionalidade punitiva, "educativa", recuperadora, a era “normal”, positiva e republicana (MOTTA, 2011, p.280).
}

Entendemos a "era normal" positiva, republicana e liberal como um conjunto de normas que deveriam ser seguidas em nome da "ordem e progresso" com a qual se pretendia conduzir a nova República, sendo o 
sujeito "criminoso" ou "vadio" considerado em disfunção social, como alguém que não foi devidamente socializado. É uma perspectiva funcionalista, que considera a educação e o trabalho como a fórmula redentora do sujeito.

Pensar as prisões no cenário brasileiro é perceber que as mesmas constituem um espaço de contradições e mediações sociais, perpassado pelos objetivos de custódia e "tratamento", caracterizando-se por um contexto de tensões entre as propostas de um Estado Democrático de Direito - instituído pela Constituição da República Federativa do Brasil de 1988 e pela Lei de Execução Penal - e a presença da disciplina, manutenção da ordem e segurança como mecanismos centrais do processo de custódia.

\section{A Lei de Execução Penal: a face da custódia e DO TRATAMENTO PENAL}

A Lei n. 7.210, de 11 de julho de 1984 (Lei de Execuções Penais - LEP) e as normativas no âmbito do sistema penitenciário brasileiro estabelecem, no seu artigo 11, o direito dos presos às formas de assistência material, à saúde, jurídica, educacional, social e religiosa. Nesse sentido, a LEP ressalta um novo olhar sobre esses indivíduos como sujeitos e cidadãos de direitos, considerando os elementos necessários à reconstrução de suas vidas.

A assistência, anunciada na LEP como direito, é ressaltada na perspectiva de efetivar ações voltadas à "recuperação" dos presos e à garantia dos serviços sociais, que possibilitam a inclusão social do indivíduo, sendo considerada como ação indispensável ao "tratamento penal", colocando o preso na condição ambígua de cidadão e, ao mesmo tempo, "sujeito em disfunção social". Draibe (1996) argumenta que, historicamente, as políticas sociais configuram-se como respostas às necessidades fundamentais ao desenvolvimento da personalidade humana e da sociedade.

As assistências pública e religiosa tornaram-se necessárias em decorrência da nova maneira de organizar a economia, a qual trazia consigo nova forma de organização social, política e religiosa, pois sem elas os pobres não sobreviveriam e poderiam se transformar em ameaça a tranquilidade social. Também algumas consequências desastrosas estão contidas no efeito de ambas. Desastrosas para os pobres, mas benéficas para os interesses do capital e seus representantes, os capitalistas (SÁ, 1996, p. 20).

A assistência social, educacional e religiosa contribui para a produção material e imaterial da vida social dos presos. Ou seja, estas assistências, além de viabilizar o acesso concreto e material a diversos serviços, produzem e reproduzem ideologicamente valores, concepções, pensamentos, visões de homem e de mundo.

$\mathrm{O}$ acesso e efetivação dos direitos sociais e das assistências, no campo da execução penal, configuram-se como a reprodução de ideologias dominantes e de controle social ou a possibilidade de elaboração de uma cultura própria dos diversos segmentos sociais. Destaca-se o papel da educação, religião e assistência social no acesso do preso à informação e conhecimento, condições imprescindíveis para o desenvolvimento de uma visão critica da realidade. Logo, as assistências - na dimensão ideológica - consistem num contexto de múltiplas contradições e num campo de disputa de poder e de luta hegemônica.

Na maioria das unidades prisionais não há infraestrutura e recursos humanos que possam garantir o atendimento (universal) e acesso de toda a população carcerária às assistências material, social, jurídica e à saúde. Logo, são atendidos prioritariamente os presos que possuem maior necessidade - socioeconômica, jurídica ou de saúde - utilizando o caráter focalista, seletivo e compensatório das políticas sociais (QUINTINO, 2006).

Nesse sentido, as prisões não constituem espaços de efetivação da cidadania plena e ampliada, mas um lugar de atendimentos pragmáticos, emergenciais e compensatórios de carências. O conceito de "cidadania regulada" construído por Santos (1979) ilustra este pragmatismo, uma vez que através da legislação se 
reconhece o status de cidadão, “cujas raízes se encontram não em um código de valores políticos, mas em um sistema de estratificação ocupacional e que, ademais, tal sistema de estratificação ocupacional é definido por norma legal" (SANTOS, 1979, p. 68).

A condição meritocrática e particularista de atenção às necessidades sociais dos presos retira sua condição de cidadão, uma vez que os critérios de acessibilidade, maior necessidade ou mesmo o critério positivista do bom comportamento restringem o acesso da população carcerária aos bens e serviços previstos na LEP.

Por outro lado, o processo de focalização e seletividade das políticas sociais no cenário brasileiro é tão intensificado que muitos sujeitos só conseguem acessar a rede de direitos de saúde, assistência social, educação e trabalho após sua privação e restrição de liberdade. A prisão pode constituir um espaço de exclusão da população historicamente considerada excluída do exercício da cidadania e, contraditoriamente, representar um processo de inclusão desta população à rede de serviços e políticas sociais.

A prisão constitui um espaço híbrido, perpassado por diversas contradições: a contradição entre a função punitiva e de tratamento penal; a contradição entre a exclusão social e a perspectiva de inclusão social; a contradição de pensar o redirecionamento de uma instituição considerada por Goffman (1974) uma “instituição total” numa sociedade global, moderna e de comunicação e relações sociais flexíveis.

Estas contradições permanecem no projeto de Lei do Senado n. 513 de 2013, que apresenta uma proposta de alteração da Lei de Execução Penal, na qual a execução penal permanece com o objetivo de efetivar as disposições de decisão criminal, proporcionando condições para o cumprimento da pena e para a harmônica integração social do condenado. A perspectiva funcionalista permanece no texto legal convivendo com a perspectiva de ampliação de espaços de consolidação de direitos e da cidadania, exemplificada na proposta de que a assistência ao preso deve incluir a obtenção de documentação, providências para a obtenção de benefícios da Previdência Social e, ainda, referenciar o preso e seus familiares junto a órgãos e instrumentos no âmbito da Lei Orgânica de Assistência Social.

A LEP e o debate sobre sua reformulação ainda não ganharam a efetividade necessária à garantia e ao acesso aos direitos da população presa. Tal efetividade, na verdade, seria configurada a partir da implantação de uma política penitenciária contínua, sob a responsabilidade do Estado (nos três níveis: federal, estadual e municipal), garantindo a intersetorialidade e integralidade das políticas públicas.

Nesse sentido, o campo da execução penal é marcado pelas mesmas características e contradições da política pública de assistência social, não configurando a efetivação de um Estado Democrático de Direito ou Estado Social.

\section{Considerações FINAIS}

O presente artigo não tem o objetivo de esgotar a temática, mas, ao contrário, de despertar o olhar crítico do leitor sobre a execução penal e as particularidades do cenário brasileiro.

A prisão é uma instituição social que tem o papel de garantir a manutenção do controle e da ordem social, não cumprindo a proposta funcionalista de ressocialização, reinserção e recuperação do sujeito, que cometeu um delito. "Parece, pois, que treinar homens para a vida livre submetendo-os a condições de cativeiro, afigura-se tão absurdo como alguém se preparar para uma corrida, ficando na cama por semanas" (THOMPSON, 2002, p. 12 e 13).

Historicamente, as formas de punição atendem aos interesses ideológicos, políticos e econômicos da estrutura social. Pensando o cenário contemporâneo, as formas punitivas e coercitivas atendem a lógica restritiva e de desmonte do Estado Social ou Estado Democrático de Direito e, paralelamente, a intensificação do Estado Penal e gestor de políticas públicas restritivas e assistencialistas.

Pensar a prisão como instituição no âmbito da sociedade capitalista, no século XXI, é desvelar a 
contradição de construções arquitetônicas que representam a pluralidade e mistura de modelos norteamericanos; o debate constante sobre a interface entre os setores público e privado no âmbito da execução penal, entre a perspectiva da terceirização e privatização; a contradição de um texto legal (a LEP) que ressalta a perspectiva das assistências (material, jurídica, educacional, social), mas que não viabiliza mecanismos de controle social.

O artigo tem a proposta não só de explicitar estas contradições, mas de evidenciar que o espaço prisional é um campo hegemônico de relações de poder, sendo caracterizado pela disseminação e reprodução ideológica dominante, mas constituindo também espaço de resistência, processo de luta e movimento contra-hegemônico.

A prisão se configura como um espaço de privação, isolamento, repetição, mas também como espaço de produção de subjetividade e de novas relações sociais. Ela não é um espaço localizado fora e isolado da sociedade, mas constitui parte da sociedade capitalista, servindo como um dos instrumentos de manutenção da estrutura social e de reprodução das relações sociais.

O preso não é um indivíduo em disfunção social, mas um sujeito caracterizado por determinada classe social e etnia, vivenciando diversas expressões da questão social. É um sujeito que vivencia no interior da prisão diversas formas de socialização e interação social, criando formas de resistência ao poder.

Fazem-se necessários estudos que problematizem e desvelem o contexto contraditório das prisões e que, principalmente, mergulhem na esfera da subjetividade e das relações sociais, caracterizando o preso como sujeito em privação de liberdade e um cidadão que deve ter acesso aos direitos sociais, previstos no âmbito da legislação penal.

\section{Notas Explicativas}

${ }^{1}$ Galé ou galera - do grego (ãäéÝá) - pode designar qualquer tipo de navio movido a remos. Algumas variações possuem mastros e velas para auxiliar a propulsão; eram navios muito usados no Mediterrâneo.

${ }^{2}$ As Ordenações Filipinas são uma compilação jurídica que resultou da reforma do Código Manuelino, por Filipe II de Espanha (Felipe I de Portugal), durante o domínio castelhano. O Livro V das Ordenações Filipinas é o diploma penal que vigorou por mais tempo no Brasil - cerca de 220 anos - desde a Lei de 11 de janeiro de 1603 até 1830, quando sobreveio o Código Criminal do Império.

${ }^{3}$ Reforma Pombalina - o Marquês de Pombal, influenciado pelos ideais iluministas, procura modernizar a administração pública portuguesa, principalmente buscando mais lucros nas colônias portuguesas, entre elas, na mais focada: o Brasil.

${ }^{4} \mathrm{~A}$ pena das galés era na qual os condenados cumpriam a pena de trabalhos forçados, espécie de antiga sanção criminal. $\mathrm{O}$ Código Criminal de 1830 adotou-a, determinando, no artigo 44, que os réus usassem calceta (argola) no pé e corrente de ferro, juntos ou separados, e que trabalhassem nos serviços públicos da província onde ocorrera o delito, à disposição do governo.

${ }^{5}$ Segundo este Código, o condenado poderia ser punido com morte, galés, prisão perpétua ou prisão com trabalho.

\section{REFERÊNCIAS BIBLIOGRÁFICAS}

ARAÚJO, C. E. M.; Entre dois cativeiros: escravidão urbana e sistema prisional no Rio de Janeiro, 1790-1821. In: MAIA, C. N. et al (Org.). História das prisões no Brasil. Rio de Janeiro: Rocco, 2009. v. 1, p.217-248.

BRASIL. Constituição (1988). Constituição da República Federativa do Brasil. Brasília, DF: Senado, 1988.

BRASIL. Lei n. 7.210, de 11 de julho de 1984. Institui a Lei de Execução Penal. Diário Oficial da República Federativa do Brasil, Brasília, DF, 13 jul. 1984.

CHAZKEL, A. Uma perigosíssima lição: a Casa de Detenção do Rio de Janeiro na Primeira República. In: MAIA, C. N. et al (Org.). História das prisões no Brasil. Rio de Janeiro: Rocco, 2009. v. 2, p.7-34.

DRAIBE, S. As políticas sociais e o neoliberalismo - reflexões suscitadas pelas experiências latino-americanas. Revista USP, n. 17, São Paulo, 1993.

FOUCALT, M. A verdade e as formas jurídicas. Cadernos da PUC-Rio, n. 16, Rio de Janeiro, 1974.

Vigiar e Punir. Nascimento da prisão. 33 ed. Petrópolis: Vozes, 1987.

GOFFMAN, E. Manicômios, prisões e conventos. São Paulo: Perspectiva, 1974.

QUINTINO, S. A. A prisão como castigo, o trabalho como remição: contradições do Sistema Penitenciário Paranaense. In: Revista Sociologia Jurídica, n. 3 (Dossiê Questões Penitenciárias), Julho-Dezembro de 2006

MOTTA, M. B. Crítica da razão punitiva: o nascimento da prisão no Brasil. Rio de Janeiro: Forense Universitária, 2011.

SÁ, G. R. A prisão dos excluídos: origens e reflexões sobre a

[SYN]THESIS, Rio de Janeiro, vol.8, n 1, 2015, p. 127 - 137 
pena privativa de liberdade. Juiz de Fora: Ed. da Univ. Federal de Juiz de Fora, 1996.

SANTOS, W. G. Cidadania e Justiça: a política social na ordem brasileira. Rio de Janeiro: Editora Campus, 1979.

SOUZA, J. P. M.. A construção da Memória dos funcionários em suas relações com o trabalho no antigo Instituto Penal Cândido Mendes em Ilha Grande. Dissertação (Mestrado em Memória Social) - Universidade Federal do Estado do Rio de Janeiro (UNIRIO), Rio de Janeiro, 2012.

THOMPSON, A. A questão penitenciária. 5. ed. Rio de janeiro: Forense, 2002. 